\title{
Coronary Artery Disease
}

\section{Executive Summary of the Japan Atherosclerosis Society (JAS) Guidelines for the Diagnosis and Prevention of Atherosclerotic Cardiovascular Diseases in Japan - 2012 Version}

\author{
Tamio Teramoto, Jun Sasaki, Shun Ishibashi, Sadatoshi Birou, Hiroyuki Daida, Seitaro Dohi, Genshi Egusa, \\ Takafumi Hiro, Kazuhiko Hirobe, Mami lida, Shinji Kihara, Makoto Kinoshita, Chizuko Maruyama, \\ Takao Ohta, Tomonori Okamura, Shizuya Yamashita, Masayuki Yokode and Koutaro Yokote
}

Committee for Epidemiology and Clinical Management of Atherosclerosis

Epidemiological and interventional studies conducted in Western countries and the results of a metaanalysis have revealed that the incidence of cardiovascular events in patients with coronary artery disease $(\mathrm{CAD})$ is higher than that observed in primary prevention patients. In Japan, the incidence of cardiovascular events in patients who receive dietary therapy was found to be 2.1/1,000 person-years in the MEGA study ${ }^{1)}$, while that in primary prevention patients using statins was found to be $0.9 / 1,000$ person-years in the J-LIT study ${ }^{2}$. In contrast, the incidence of cardiovascular events in patients with CAD was found to be 4.5/1,000 person-years in the J-LIT study ${ }^{3)}$ and $6.8 / 1,000$ person-years in the JELIS study ${ }^{4)}$. The $\mathrm{JCAD}^{5)}$ and CREDO-Kyoto studies ${ }^{6}$, registry studies of patients with $\mathrm{CAD}$, both reported a high incidence of cardiovascular events of $\geq 15 / 1,000$ person-years. Moreover, among patients with CAD, those with the conditions listed in Table $\mathbf{1}$ are at higher risk. It has been reported that such patients have a clearly higher incidence of coronary events, even when the LDLcholesterol (LDL-C) level is managed to the same extent as in patients without complications.

\section{Acute Coronary Syndrome}

Patients with acute coronary syndrome (ACS) have a higher risk of recurrence of cardiovascular events than patients with stable CAD. The OACISLIPID study investigated the inhibitory effects of early statin treatment on cardiovascular events in Japanese patients with acute myocardial infarction $(\mathrm{MI})^{7)}$. In that study, the incidence of total mortality and nonfatal MI in patients who received lipid-lowering therapy

Received: April 10, 2013

Accepted for publication: June 18, 2013
Table 1. Patient Conditions Requiring More Strict Management for Secondary Prevention

- Acute coronary syndrome

- Smoking

- DM

- $\mathrm{CKD}$

- Noncardiogenic cerebral infarction/PAD

- Metabolic syndrome

- Multiple risk factors

other than statins was 40/1,000 person-years, while that among patients who received statins was 30/1,000 person-years, thus revealing a remarkably high incidence of cardiovascular events.

Meanwhile, it has been reported that the administration of LDL-C-lowering therapy from the early stage of ACS is effective in preventing cardiovascular events $^{8)}$ and that more intensive LDL-C-lowering therapy decreases the incidence of cardiovascular events more significantly than typical LDL-C-lowering therapy ${ }^{9)}$. A meta-analysis of randomized controlled trials (RCTs) of statin treatment started within 14 days after the onset of ACS demonstrated no protective effects on cardiovascular events in a short period of four months ${ }^{10)}$; however, the incidence of cardiovascular events was significantly reduced during an observation period of $\geq 2$ years ${ }^{11)}$. These results suggest that the beneficial effects of providing early, intensive LDL-Clowering therapy in preventing cardiovascular events are observed from four to 12 months after the onset of ACS.

In Japan, the effectiveness of early LDL-C-lowering therapy in patients with ACS has been investigated by observing coronary artery plaque using intravascu- 
lar ultrasonography (IVUS). In the ESTABLISH study, the administration of early, intensive LDL-C-lowering therapy after the onset of ACS decreased the mean LDL-C level to $70 \mathrm{mg} / \mathrm{dL}$ after six months, resulting in a decrease in the plaque volume of $13.1 \%{ }^{12}$. The changes in plaque volume were found to be significantly and positively correlated with the LDL-C level after treatment and the rate of decrease in the LDL-C level. The ESTABLISH study followed up (mean: 4.2 years) additional patients and reported that the administration of early, intensive LDL-C-lowering therapy after the onset of ACS significantly decreased cardiovascular events ${ }^{13)}$. Furthermore, the JAPAN-ACS study demonstrated that providing early, intensive LDL-Clowering therapy using statins in patients with ACS was effective in inhibiting plaque progression ${ }^{14)}$; however, that study found no significant relationships between the changes in the LDL-C level during treatment or the LDL-C level observed after treatment and the rate of plaque regression.

\section{Smoking}

In patients with CAD who continue to smoke, the risk of recurrence of cardiovascular events is higher than that observed in nonsmokers and the risk of fatal cardiovascular events, including total mortality, cardiac death and sudden cardiac death, is significantly increased $^{15-19)}$. In the REACH Registry, a registry study of patients with cardiovascular disease [CAD, cerebrovascular disease and peripheral arterial disease (PAD)] or more than one risk factor for atherosclerosis, the incidence of cardiovascular events in patients who continued to smoke was approximately 1.3-fold higher than that observed in lifelong nonsmokers ${ }^{20}$. In the OACIS study, even after adjusting for age, sex, diabetes mellitus (DM), hypertension, dyslipidemia, and therapeutic drugs, the risk of total mortality in patients who continued to smoke after the onset of MI was 2.3-fold higher than that observed in lifelong nonsmokers. In contrast, the risk of total mortality in patients who stopped smoking after the onset of MI was as low as that observed in lifelong nonsmokers and was significantly decreased (by 61\%) compared with that observed in patients who continued to smoke ${ }^{21)}$. Many epidemiological studies have reported that the risk of recurrence of cardiovascular events decreases after approximately half a year following the cessation of smoking and reaches almost the same level as that observed in lifelong nonsmokers approximately 10 years after smoking cessation, regardless of age and sex ${ }^{15-22)}$.

A subanalysis of the secondary prevention studies, TNT and IDEAL ${ }^{23)}$, showed that the risk of car- diovascular events in continued smokers is higher than that observed in lifelong nonsmokers, even among those receiving intensive LDL-C-lowering therapy with statins. Therefore, providing smoking cessation instructions to patients who continue to smoke is extremely important.

\section{Multiple Risk Factors and Metabolic Syndrome}

The results of a meta-analysis revealed that patients with CAD complicated by metabolic syndrome have a higher risk of total mortality and cardiovascular events $^{24)}$.

A subanalysis of the TNT study of patients with stable $\mathrm{CAD}$ and metabolic syndrome demonstrated the risk of cardiovascular events to increase in association with the presence of each additional component of metabolic syndrome. In particular, patients with three or more major risk factors have a higher incidence of cardiovascular events. However, high-dose statin treatment has been shown to significantly decrease the rate of cardiovascular events (by 29\%) compared with usual-dose statin treatment ${ }^{25)}$.

The JCAD, an observational study conducted in Japan, demonstrated that the risk of cardiovascular events in patients with three or more major risk factors is 1.3-fold higher than that observed in patients with two or less risk factors ${ }^{5)}$. In a study in which patients who underwent percutaneous coronary intervention (PCI) were followed up for a long period, the relative risk of cardiovascular events in the patients with metabolic syndrome was 2.1 -fold $^{26}$; however, statin treatment resulted in a significant decrease in total mortality of $44 \%$ and coronary death of $47 \%{ }^{27)}$.

\section{Diabetes Mellitus (DM)}

It has been reported that the risk of recurrence of cardiovascular events is increased in the presence of $\mathrm{DM}$ in patients with a history of $\mathrm{MI}^{28-31)}$. Epidemiological studies of Japanese patients with CAD have also reported that the risk of total mortality and cardiovascular events in patients with DM is high ${ }^{5,32,33)}$. Moreover, an analysis of patients with CAD in the J-LIT study showed that the relative risk of cardiovascular events is increased approximately 2.5 -fold in the presence of $\mathrm{DM}^{3,7)}$.

According to the CTT, a meta-analysis of 14 RCTs of statins, the beneficial effects of statins on cardiovascular events are observed regardless of the presence or absence of $\mathrm{DM}$ or $\mathrm{CAD}^{34)}$. A subanalysis of the TNT study of patients with CAD and DM showed that high-dose statin treatment significantly decreases cardiovascular and cerebrovascular events by $25 \%$ and $31 \%$, respectively, compared with usual-dose 
statin treatment ${ }^{35)}$.

A meta-analysis of clinical studies using IVUS conducted in Western countries reported that DM is an independent risk factor in patients whose coronary plaque volume is $\geq 5 \%$ despite having a decreased LDL-C level of $\leq 70 \mathrm{mg} / \mathrm{dL}$ with treatment ${ }^{36}$. It has also been reported that there is a significant positive relationship between an increase in the coronary plaque volume, as well as the LDL-C level, and the incidence of cardiovascular events after treatment. This suggests that the use of intensive LDL-C-lowering therapy is important in patients with CAD complicated by DM. Furthermore, in a subanalysis of the JAPAN-ACS study conducted in patients with ACS in Japan $^{37)}$, DM was found to be a strong negative risk factor for plaque regression. In addition, although the LDL-C-lowering effects of statins were equivalent to those observed in patients without DM, the effects on plaque volume regression were significantly decreased in patients with DM. However, it has been reported that significant plaque regression effects can be obtained if the LDL-C level is maintained at $<75 \mathrm{mg} /$ $\mathrm{dL}^{38)}$.

\section{Noncardiogenic Cerebral Infarction and Periph- eral Arterial Disease (PAD)}

Cardiovascular diseases, such as CAD, cerebrovascular disease and PAD, which commonly occur in patients with atherosclerosis, interact, leading to a risk of systemic vascular complications. The REACH registry revealed that approximately $16 \%$ of patients have two or more cardiovascular diseases ${ }^{39}$. In a comparison of the results of the CREDO-Kyoto study conducted in Japan with those of a registry study conducted in the U.S. ${ }^{33)}$, the complication rate of cerebrovascular disease was significantly higher in Japan ( $16.4 \%$ vs. $5.0 \%$ ), while the complication rate of PAD was significantly higher in the U.S.; however, both complications were confirmed to be high risk factors for cardiovascular events in Japan and the U.S.

\section{1) Noncardiogenic Cerebral Infarction}

Secondary prevention studies of CAD conducted in Western countries, such as the 4S, LIPID and CARE studies, have reported that patients with CAD with a history of cerebrovascular disease have a high risk of recurrence of cerebrovascular and cardiovascular events, although LDL-C-lowering therapy with statins decreases the risk of recurrence of both cerebrovascular and cardiovascular events ${ }^{40-42)}$.

\section{2) Peripheral Arterial Disease (PAD)}

Although patients with PAD with a history of
CAD have an extremely high risk of total mortality and fatal cardiovascular events ${ }^{43-48)}$, there are no lipid intervention studies focusing only on patients with PAD complicated by CAD. In a meta-analysis of the effectiveness of lipid intervention in patients with PAD, lipid-lowering therapy was found to decrease the incidence of cardiovascular events by $20 \%$ and total mortality by $14 \%{ }^{49)}$. Subanalyses of cohort studies and RCTs have reported the effectiveness of statins in patients with $\mathrm{PAD}^{50-54)}$

A meta-analysis of clinical studies in which the progression of coronary plaque lesions was analyzed using IVUS showed that effects on the inhibition of the progression and regression of plaque are observed when the LDL-C level is maintained at $<70 \mathrm{mg} / \mathrm{dL}$, regardless of the presence or absence of PAD, and that plaque regression is related to cardiovascular events ${ }^{55)}$.

\section{Chronic Kidney Disease (CKD)}

Analyses of long-term observational studies of patients with ACS and those who have undergone PCI stratified according to the estimated glomerular filtration rate (eGFR) have reported that the risk of cardiovascular events, including cerebrovascular disease, cardiac death and total mortality, in patients with mild chronic kidney disease (CKD) increases by 2 - to 3 -fold compared with patients with a normal renal function, and the risk further increases in association with the severity of renal dysfunction ${ }^{56,57)}$, The CREDO-Kyoto study reported that, among patients with CKD who have undergone PCI, the risk of cardiovascular death is increased by 2.9-fold and the risk of total mortality is increased by 2.1 -fold. In particular, patients $\leq 55$ years of age were found to have an increased risk of cardiovascular events, including cerebrovascular disease (by 3.7-fold) ${ }^{58)}$. Furthermore, patients with CKD and a serum creatinine level of $\geq 2.0 \mathrm{mg} / \mathrm{dL}$ were found to have a 7.0-fold increased risk of total mortality. This suggests that patients with CKD who have undergone PCI have an increased risk of cardiovascular events ${ }^{33)}$.

The protective effects of lipid-lowering therapy on cardiovascular events in patients with CKD complicated by CAD have been investigated in a post hoc analysis of early secondary prevention studies using statins. The results showed that statins provide significant beneficial effects on cardiovascular events, but not cerebrovascular disease, in patients with mild CKD and an eGFR of $<75 \mathrm{~mL} / \mathrm{min} / 1.73 \mathrm{~m}^{259,60)}$. Furthermore, a post hoc analysis of secondary prevention studies reported that high-dose statin treatment significantly decreases the incidence of cardiovascular events by approximately $30 \%$ in patients with moderate 
CKD compared with usual-dose statin treatment ${ }^{61,62)}$.

\section{Footnotes}

This is an English version of the guidelines of the Japan Atherosclerosis Society (Chapter 11) published in Japanese in June 2012.

\section{Acknowledgements}

We are grateful to the following societies for their collaboration and valuable contributions: Dr. Hidenori Arai (The Japan Geriatrics Society), Dr. Kiminori Hosoda (Japan Society for the Study of Obesity), Dr. Hiroyasu Iso (Japan Epidemiological Association), Dr. Atsunori Kashiwagi (Japan Diabetes Society), Dr. Masayasu Matsumoto (The Japan Stroke Society), Dr. Hiromi Rakugi (The Japanese Society of Hypertension), Dr. Tetsuo Shoji (Japanese Society of Nephrology) and Dr. Hiroaki Tanaka (Japanese Society of Physical Fitness and Sports Medicine). We also thank Dr. Shinji Koba, Dr. Manabu Minami, Dr. Tetsuro Miyazaki, Dr. Hirotoshi Ohmura, Dr. Mariko HaradaShiba, Dr. Hideaki Shima, Dr. Daisuke Sugiyama, Dr. Minoru Takemoto and Dr. Kazuhisa Tsukamoto for supporting this work.

\section{References}

1) Nakamura H, Arakawa K, Itakura H, Kitabatake A, Goto Y, Toyota T, Nakaya N, Nishimoto S, Muranaka M, Yamamoto A, Mizuno K, Ohashi Y: for the MEGA Study Group: Primary prevention of cardiovascular disease with pravastatin in Japan (MEGA Study): a prospective randomized controlled trial. Lancet, 2006; 368: 1155-1163

2) Matsuzaki M, Kita T, Mabuchi H, Matsuzawa Y, Nakaya N, Oikawa S, Saito Y, Sasaki J, Shimamoto K, Itakura H; J-LIT Study Group: Large scale cohort study of the relationship between serum cholesterol concentration and coronary events with low-dose simvastatin therapy in Japanese patients with hypercholesterolemia: primary prevention cohort study of the Japan Lipid Intervention Trial (J-LIT). Circ J, 2002; 66: 1087-1095

3) Mabuchi H, Kita T, Matsuzaki M, Matsuzawa Y, Nakaya N, Oikawa S, Saito Y, Sasaki J, Shimamoto K, Itakura H; J-LIT Study Group. Japan Lipid Intervention Trial: Large scale cohort study of the relationship between serum cholesterol concentration and coronary events with low-dose simvastatin therapy in Japanese patients with hypercholesterolemia and coronary heart disease: secondary prevention cohort study of the Japan Lipid Intervention Trial (J-LIT). Circ J, 2002; 66: 1096-1100

4) Matsuzaki M, Yokoyama M, Saito Y, et al; JELIS Investigators: Incremental effects of eicosapentaenoic acid on cardiovascular events in statin-treated patients with coronary artery disease. Circ J, 2009; 73: 1283-1290
5) Japanese Coronary Artery Disease (JCAD) Study Investigators: Current status of the background of patients with coronary artery disease in Japan. Circ J, 2006; 70: 12561262

6) Furukawa Y, Taniguchi R, Ehara N, Ozasa N, Haruna Y, Saito N, Doi T, Hoshino K, Shizuta S, Morimoto T, Imai Y, Teramukai S, Fukushima M, Kita T, Kimura T; CREDO-Kyoto Investigators: Better survival with statin administration after revascularization therapy in Japanese patients with coronary artery disease: perspectives from the CREDO-Kyoto registry. Circ J, 2008; 72: 1937-1945

7) Sato H, Kinjo K, Ito H, Hirayama A, Nanto S, Fukunami M, Nishino M, Lim YJ, Kijima Y, Koretsune Y, Nakatani D, Mizuno H, Shimizu M, Hori M; Osaka Acute Coronary Insufficiency Study (OACIS)-LIPID Study Investigators: Effect of early use of low dose pravastatin on major adverse cardiac events in patients with acute myocardial infarction: The OACIS-LIPID Study. Cir J, 2008; 72: $17-22$

8) Schwartz GG, Olsson AG, Ezekowitz MD, Ganz P, Oliver MF, Waters D, Zeiher A, Chaitman BR, Leslie S, Stern T: Myocardial Ischemia Reduction with Aggressive Cholesterol Lowering (MIRACL) Study Investigators: Effects of atorvastatin on early recurrent ischemic events in acute coronary syndromes: the MIRACL study: a randomized controlled trial. JAMA, 2001; 285: 1711-1718

9) Cannon CP, Braunwald E, McCabe CH, Rader DJ, Rouleau JL, Belder R, Joyal SV, Hill KA, Pfeffer MA, Skene AM; Pravastatin or Atorvastatin Evaluation and Infection Therapy-Thrombolysis in Myocardial Infarction 22 Investigators: Intensive versus moderate lipid lowering with statins after acute coronary syndromes. N Engl J Med, 2004; 350: 1495-1504

10) Briel M, Schwartz GG, Thompson PL, de Lemos JA, Blazing MA, van Es GA, Kayikçioglu M, Arntz HR, den Hartog FR, Veeger NJ, Colivicchi F, Dupuis J, Okazaki S, Wright RS, Bucher HC, Nordmann AJ: Effects of early treatment with statins on short-term clinical outcomes in acute coronary syndromes: a meta 170 analysis of randomized controlled trials. JAMA, 2006; 295: 2046-2056

11) Hulten E, Jackson JL, Douglas K, George S, Villines TC: The effect of early, intensive statin therapy on acute coronary syndrome: a meta-analysis of randomized controlled trials. Arch Intern Med, 2006; 166: 1814-1821

12) Okazaki S, Yokoyama T, Miyauchi K, Shimada K, Kurata T, Sato H, Daida H: Early statin treatment in patients with acute coronary syndrome: demonstration of the beneficial effect on atherosclerotic lesions by serial volumetric intravascular ultrasound analysis during half a year after coronary event: The ESTABLISH Study. Circulation, 2004; 110: 1061-1068

13) Dohi T, Miyauchi K, Okazaki S, Yokoyama T, Yanagisawa N, Tamura H, Kojima T, Yokoyama K, Kurata T, Daida H: Early intensive statin treatment for six months improves long-term clinical outcomes in patients with acute coronary syndrome (Extended-ESTABLISH trial): a follow-up study. Atherosclerosis, 2010; 210: 497-502

14) Hiro T, Kimura T, Morimoto T, Miyauchi K, Nakagawa Y, Yamagishi M, Ozaki Y, Kimura K, Saito S, Yamaguchi T, Daida H, Matsuzaki M; JAPAN-ACS Investigators: 
Effect of intensive statin therapy on regression of coronary atherosclerosis in patients with acute coronary syndrome: a multicenter randomized trial evaluated by volumetric intravascular ultrasound using pitavastatin versus atorvastatin (JAPAN-ACS [Japan Assessment of Pitavastatin and Atorvastatin in Acute Coronary Syndrome] study). J Am Coll Cardiol, 2009; 54: 293-302

15) Goldenberg I, Jonas M, Tenenbaum A, Boyko V, Matetzky S, Shotan A, Behar S, Reicher-Reiss H; Bezafibrate Infarction Prevention Study Group: Current smoking, smoking cessation, and the risk of sudden cardiac death in patients with coronary artery disease. Arch Intern Med, 2003; 163: 2301-2305

16) Critchley JA, Capewell S: Mortality risk reduction associated with smoking cessation in patients with coronary heart disease: a systematic review. JAMA, 2003; 290: 86-97

17) van Domburg RT, Meeter K, van Berkel DF, Veldkamp RF, van Herwerden LA, Bogers AJ: Smoking cessation reduces mortality after coronary artery bypass surgery: a 20-year follow-up study. J Am Coll Cardiol, 2000; 36: 878-883

18) Rea TD, Heckbert SR, Kaplan RC, et al: Smoking status and risk for recurrent coronary events after myocardial infarction. Ann Intern Med, 2002; 137: 494-500

19) Wilson K, Gibson N, Willan A, Cook D: Effects of smoking cessation on mortality after myocardial infarction: meta-analysis of cohort studies. Arch Intern Med, 2000; 160: 939-944

20) REACH Registry Investigators: Comparative determinants of 4-year cardiovascular event rates in stable outpatients at risk of or with atherothrombosis. JAMA, 2010; 304: 1350-1357

21) Kinjo K, Sato H, Sakata $Y$, Nakatani D, Mizuno H, Shimizu M, Sasaki T, Kijima Y, Nishino M, Uematsu M, Tanouchi J, Nanto S, Otsu K, Hori M; Osaka Acute Coronary Insufficiency Study (OACIS) Group: Impact of smoking status on long-term mortality in patients with acute myocardial infarction. Circ J, 2005; 69: 7-12

22) Baba $S$, Iso H, Mannami T, Sasaki S, Okada K, Konishi M; Shoichiro Tsugane; JPHC Study Group: Cigarette smoking and risk of coronary heart disease incidence among middle-aged Japanese men and women: the JPHC Study Cohort I. Eur J Cardiovasc Prev Rehabil, 2006; 13: 207-213

23) Frey P, Waters DD, DeMicco DA, Breazna A, Samuels L, Pipe A, Wun CC, Benowitz NL: Impact of smoking on cardiovascular events in patients with coronary disease receiving contemporary medical therapy (from the Treating to New Targets [TNT] and the Incremental Decrease in End Points Through Aggressive Lipid Lowering [IDEAL] Trials). Am J Cardiol, 2011; 107: 145-150

24) Mottillo S, Filion KB, Genest J, Joseph L, Pilote L, Poirier P, Rinfret S, Schiffrin EL, Eisenberg MJ: The metabolic syndrome and cardiovascular risk: A systematic review and meta-analysis. J Am Coll Cardiol, 2010; 56: 1113-1132

25) Deedwania P, Barter P, Carmena R, Fruchart JC, Grundy SM, Haffner S, Kastelein JJ, LaRosa JC, Schachner H, Shepherd J, Waters DD; Treating to New Targets Investigators: Reduction of lowdensity lipoprotein cholesterol in patients with coronary heart disease and metabolic syn- drome: analysis of the Treating to New Targets study. Lancet, 2006; 368: 919-928

26) Kasai T, Miyauchi K, Kurata T, Okazaki S, Kajimoto K, Kubota N, Daida H: Impact of metabolic syndrome among patients with and without diabetes mellitus on long-term outcomes after percutaneous coronary intervention. Hypertens Res, 2008; 31: 235-241

27) Kasai T, Miyauchi K, Kajimoto K, Kubota N, Kurata T, Amano A, Daida H: The impact of pravastatin therapy on long-term outcomes in patients with metabolic syndrome undergoing complete coronary revascularization. Circ J, 2009; 73: 2104-2109

28) Levantesi G, Macchia A, Marfisi R, Franzosi MG, Maggioni AP, Nicolosi GL, Schweiger C, Tavazzi L, Tognoni G, Valagussa F, Marchioli R; GISSIP revenzione Investigators: Metabolic syndrome and risk of cardiovascular events after myocardial infarction. J Am Coll Cardiol, 2005; 46: 277-283

29) Donahoe SM, Stewart GC, McCabe CH, Mohanavelu S, Murphy SA, Cannon CP, Antman EM: Diabetes and mortality following acute coronary syndromes. JAMA, 2007; 298: 765-775

30) Costa J, Borges M, David C, Vaz Carneiro A: Efficacy of lipid lowering drug treatment for diabetic and nondiabetic patients: meta-analysis of randomised controlled trials. BMJ, 2006; 332: 1115-1124

31) Cholesterol Treatment Trialists' (CTT) Collaborators: Efficacy of cholesterol-lowering therapy in 18686 people with diabetes in 14 randomised trials of statins: a metaanalysis. Lancet, 2008; 371: 117-125

32) Takara A, Ogawa H, Endoh Y, Mori F, Yamaguchi J, Takagi A, Koyanagi R, Shiga T, Kasanuki H, Hagiwara N: Long-term prognosis of diabetic patients with acute myocardial infarction in the era of acute revascularization. Cardiovascular Diabetology, 2010; 366: 9: 1-7

33) Kohsaka S, Kimura T, Goto M, Lee VV, Elayda M, Furukawa Y, Fukushima M, Komeda M, Sakata R, Willerson JT, Wilson JM, Kita T: Difference in patient profiles and outcomes in Japanese versus American patients undergoing coronary revascularization (Collaborative study by CREDO-Kyoto and the Texas Heart Institute Research database). Am J Cardiol, 2010; 105: 1698-1704

34) Baigent C, Keech A, Kearney PM, Blackwell L, Buck G, Pollicino C, Kirby A, Sourjina T, Peto R, Collins R, Simes R; Cholesterol Treatment Trialists' (CTT) Collaborators: Efficacy and safety of cholesterol-lowering treatment: prospective meta-analysis of data from 90,056 participants in 14 randomised trials of statins. Lancet, 2005; 366: 12671278

35) Shepherd J, Barter P, Carmena R, Deedwania P, Fruchart JC, Haffner S, Hsia J, Breazna A, LaRosa J, Grundy S, Waters D; Treating to New Targets Investigators: Effects of lowering LDL cholesterol substantially below currently recommended levels in patients with coronary heart disease and diabetes: The Treating to New Targets (TNT) study. Diabetes Care, 2006; 29: 1220-1226

36) Bayturan O, Kapadia S, Nicholls SJ, Tuzcu EM, Shao M, Uno K, Shreevatsa A, Lavoie AJ, Wolski K, Schoenhagen P, Nissen SE: Clinical predictors of plaque progression despite very low levels of low-density lipoprotein choles- 
terol. J Am Coll Cardiol, 2010; 55: 2736-2742

37) Hiro T, Kimura T, Morimoto T, Miyauchi K, Nakagawa Y, Yamagishi M, Ozaki Y, Kimura K, Saito S, Yamaguchi T, Daida H, Matsuzaki M; JAPANACS Investigators: Diabetes mellitus is a major negative determinant of coronary plaque regression during statin therapy in patients with acute coronary syndrome-serial intravascular ultrasound observations from the Japan Assessment of Pitavastatin and Atorvastatin in Acute Coronary Syndrome Trial (the JAPAN-ACS Trial). Circ J, 2010; 74: 1165-1174

38) Arai H, Hiro T, Kimura T, Morimoto T, Miyauchi $K$, Nakagawa Y, Yamagishi M, Ozaki Y, Kimura K, Saito S, Yamaguchi T, Daida H, Matsuzaki M; JAPAN-ACS Investigators: More intensive lipid lowering is associated with regression of coronary atherosclerosis in diabetic patients with acute coronary syndrome-sub-analysis of JAPAN-ACS study. J Athroscler Thromb, 2010; 17: 10961107

39) Bhatt DL, Steg PG, Ohman EM, Hirsch AT, Ikeda Y, Mas JL, Goto S, Liau CS, Richard AJ, Röther J, Wilson PW; REACH Registry Investigators: International prevalence, recognition, and treatment of cardiovascular risk factors in outpatients with atherothrombosis. JAMA, 2006; 295: 180-189

40) Scandinavian Simvastatin Survival Study group: Randomised trial of cholesterol lowering in 4444 patients with coronary heart disease: the Scandinavian Simvastatin Survival Study (4S). Lancet, 1994; 344: 1383-1389

41) The Long-term Intervention with Pravastatin in Ischaemic Disease (LIPID) study group: Prevention of cardiovascular events and death with pravastatin in patients with coronary heart disease and a broad range of initial cholesterol levels. N Engl J Med, 1998; 339: 1349-1357

42) Plehn JF, Davis BR, Sacks FM, Rouleau JL, Pfeffer MA, Bernstein V, Cuddy TE, Moyé LA, Piller LB, Rutherford J, Simpson LM, Braunwald E: Reduction of stroke incidence after myocardial infarction with pravastatin: The Cholesterol and Recurrent Events (CARE) study. Circulation, 1999; 99: 216-223

43) Criqui MH, Langer RD, Fronek A, Feigelson HS, Klauber MR, McCann TJ, Browner D: Mortality over a period of 10 years in patients with peripheral arterial disease. $\mathrm{N}$ Engl J Med, 1992; 326: 381-386

44) Steg PG, Bhatt DL, Wilson PW, D'Agostino R Sr, Ohman EM, Röther J, Liau CS, Hirsch AT, Mas JL, Ikeda Y, Pencina MJ, Goto S; REACH Registry Investigators: Oneyear cardiovascular event rates in outpatients with atherothrombosis. JAMA, 2007; 297: 1197-1206

45) Newman AB, Shemanski L, Manolio TA, Cushman M, Mittelmark M, Polak JF, Powe NR, Siscovick D; Cardiovascular Health Study Collaborative Research Group: Ankle-arm index as a predictor of cardiovascular disease and mortality in the Cardiovascular Health Study. Artherioscle Thromb Vasc Biol, 1999; 19: 538-545

46) McDermott MM, Mandapat AL, Moates A, Albay M, Chiou E, Celic L, Greenland P: Knowledge and attitudes regarding cardiovascular disease risk and prevention in patients with coronary or peripheral arterial disease. Arc Intern Med, 2003; 163: 2157-2162

47) Golomb BA, Dang TT, Criqui MH: Peripheral arterial disease: morbidity and mortality implications. Circulation, 2006; 114: 688-699

48) Sprengers RW, Janssen KJ, Moll FL, Verhaar MC, van der Graaf Y; SMART Study Group; SMART Study Group: Prediction rule for cardiovascular events and mortality in peripheral arterial disease patients: data from the prospective Second Manifestations of Arterial disease (SMART) cohort study. J Vasc Surg, 2009; 50: 1369-1377

49) Aung PP, Maxwell HG, Jepson RG, Price JF, Leng GC: Lipid-lowering for peripheral arterial disease of the lower limb. Cochrane Database Syst Rev, CD000123, 2007

50) Schanzer A, Hevelone N, Owens CD, Beckman JA, Belkin M, Conte MS: Statins are independently associated with reduced mortality in patients undergoing infrainguinal bypass graft surgery for critical limb ischemia. J Vasc Surg, 2008; 47: 774-781

51) Heart Protection Study Collaborative Group: Randomized trial of the effects of cholesterol lowering with simvastatin on peripheral vascular and other major vascular outcomes in 20,536 people with peripheral arterial disease and other high-risk conditions. J Vasc Surg, 2007; 45: 645-654

52) Feringa HH, van Waning VH, Bax JJ, Elhendy A, Boersma E, Schouten O, Galal W, Vidakovic RV, Tangelder MJ, Poldermans D: Cardioprotective medication is associated with improved survival in patients with peripheralarterial disease. J Am Coll Cardiol, 2006; 47: 1182-1187

53) Hoeks SE, Scholte Op Reimer WJ, Schouten O, Lenzen MJ, van Urk H, Poldermans D: Statin use in the elderly: results from a peripheral vascular survey in The Netherlands. J Vasc Surg, 2008; 48: 891-896

54) Daskalopoulou SS, Daskalopoulos ME, Mikhailidis DP, Liapis CD: Lipid management and peripheral arterial disease. Curr Drug Targets, 2007; 8: 561-570

55) Hussein AA, Uno K, Wolski K, Kapadia S, Schoenhagen P, Tuzcu EM, Nissen SE, Nicholls SJ: Peripheral arterial disease and progression of coronary atherosclerosis. J Am Coll Cardiol, 2011; 57: 1220-1225

56) Kasai $T$, Miyauchi K, Kajimoto K, Kubota N, Dohi $T$, Tsuruta R, Ogita M, Yokoyama T, Amano A, Daida H.1: Prognostic significance of glomerular filtration rate estimated by the Japanese equation among patients who underwent complete coronary revascularization. Hypertens Res, 2011; 34: 378-383

57) Dohi T, Miyauchi K, Okazaki S, Yokoyama T, Tamura H, Kojima T, Yokoyama K, Kurata T, Daida H: Long-term impact of mild chronic kidney disease in patients with acute coronary syndrome undergoing percutaneous coronary interventions. Nephrol Dial Transplant, 2011; 26: 2906-2911

58) Furukawa $Y$, Ehara N, Taniguchi R, Haruna Y, Ozasa N, Saito N, Doi T, Hoshino K, Tamura T, Shizuta S, Abe M, Toma M, Morimoto T, Teramukai S, Fukushima M, Kita T, Kimura T; CREDO-Kyoto Investigators: Coronary risk factor profile and prognostic factors for young Japanese patients undergoing coronary revascularization. Circ J, 2009; 73: 1459-1465

59) Chonchol M, Cook T, Kjekshus J, Pedersen TR, Lindenfeld J: Simvastatin for secondary prevention of all-cause mortality and major coronary events in patients with mild 
chronic renal insufficiency. Am J Kidney Dis, 2007; 49: 373-382

60) Tonelli M, Moyé L, Sacks FM, Kiberd B, Curhan G; Cholesterol and Recurrent Events (CARE) trial investigators: Pravastatin for secondary prevention of cardiovascular events in persons with mild chronic renal insufficiency. Ann Intern Med, 2003; 138: 98-104

61) Koren MJ, Davidson MH, Wilson DJ, Fayyad RS, Zuckerman A, Reed DP; ALLIANCE Investigators: Focused atrovasttin therapy in managed-care patients with coro- nary heart disease and CKD. Am J Kidney Dis, 2009; 53: $741-750$

62) Shepherd J, Kastelein JJ, Bittner V, Deedwania P, Breazna A, Dobson S, Wilson DJ, Zuckerman A, Wenger NK; TNT (Treating to New Targets) Investigators: Intensive lipid lowering with atorvastatin in patients with coronary heart disease and chronic kidney disease: the TNT (Treating to New Targets) study. J Am Coll Cardiol, 2008; 51: $1448-1454$ 